\title{
Needs and expectations of a new learning space: Research students' perspectives
}

\author{
Sandris Zeivots \\ School of Education, University of Technology Sydney \\ Sandra Schuck \\ Faculty of Arts and Social Sciences, University of Technology Sydney
}

\begin{abstract}
Much of the literature on university learning spaces focuses on the undergraduate student experience, neglecting experiences of research students in new spaces. This article is concerned with research students' needs and expectations of a learning space. It focuses on a recently opened shared activity-based learning space that was specifically built for research students. The methodological focus draws on case study methods and hermeneutic phenomenology to observe students' lived experience in the new space and how they make sense of it. Twenty-six data sets, involving interviews, surveys and feedback, were collected from research students. The findings were analysed across three themes: physical, virtual, and hybrid space; a space free of distractions; and belonging to, and interaction with, university community. The article indicates the benefits of the new space for research students and articulates the particular needs of research students in such spaces.
\end{abstract}

\section{Introduction}

Research shows that learning spaces significantly affect the way humans learn (Beckers, Van der Voordt, \& Dewulf, 2016). There is, however, a limited understanding of how the learning space impacts university students' work, for instance, their learning engagement (Sawers, Wicks, Mvududu, Seeley, \& Copeland 2016), gains (Vercellotti, 2017), and outcomes (Ellis \& Goodyear, 2016). There is an increasing need to study what promotes and inhibits their learning practices (Bruno \& Dell'Aversana, 2018).

This article presents the findings of an exploratory study on a shared activity-based workspace (hereafter, the Space) specifically built for research students. Research students from two faculties at the University of Technology Sydney (UTS) in Australia piloted use of the Space. The term research students is used to describe doctoral and master's by research students in this study. The article captures the experiences of the Faculty of Arts and Social Sciences (FASS) research students using the new learning space.

The Space is the first of its kind at UTS and is based on recent research developments concerning practices in new learning spaces. It includes individual pods, collaborative areas, quiet rooms, and project areas. It is also free of desktop computers.

The study aims to contribute to an emerging body of knowledge by understanding the needs and expectations of research students for a provided learning space. The results will inform stakeholders, not only university planners and developers, but also research supervisors and other scholars concerned with how learning spaces can support and constrain the experiences of research students.

\section{Background}

The ways people work, learn and play are changing rapidly as innovative learning spaces, mobile technologies such as smartphones and tablets, and opportunities to integrate physical and virtual spaces become increasingly common (McNeil \& Borg, 2018). Along with these changes, there is a growing interest among scholars in the use of activity-based learning spaces (Strayer, 2012) and multifunctional devices (Pegrum, 2016) that support learning.

The idea of activity-based workplaces originated in industry (Gou, 2016) and developed with the perceived need for new workplace strategies: "Re-engineering is driving not only how companies do their work, but the design of the space in which that work is done" (Becker, 1985, p. 2). It is argued that flexible use of space provides people with a greater degree of autonomy in terms of working location, tools, content and timing (Inamizu, 2013; Van der Voordt, 2004). For the purposes of this paper, an activity-based learning 
space is understood as a place where work is seen as an activity that is not necessarily bound to a certain place for it to influence a mobile and dynamic work life (Skogland, 2017).

In recent years there has been an increasing emphasis placed on the design of new learning spaces and their impact on learning (de la Harpe \& Mason, 2014). Beichner (2014) identifies three reasons that learning spaces are changing. First, the world is rapidly changing, and students expect more connection with information, technology and people as they learn; for example, the removal of mobile technologies during classes contradicts what students are used to and has little relationship to their everyday practices. Second, information is often required to be accessible wherever and whenever needed; the connectivity of smartphones and tablets enable them to provide information in a matter of seconds. Third, learning spaces change because students change. The ways students remember, locate and modify information is transforming significantly. Educators no longer hold the monopoly on information, which means that students increasingly seek answers beyond the teacher. This paper is concerned with understanding how these changes apply to students, especially research students.

Just as students change the ways they live and learn, so do educational institutions. There is a growing view that universities should be innovative and build their campuses and learning spaces to meet the expectations of tomorrow's students (Wilson \& Randall, 2012) and future workplaces (Boud, 2016). The traditional idea of the learning space is shifting away from the familiar classroom arrangement and towards activity-based learning spaces where students can actively participate in, and take charge of, their learning (Lundström, Savolainen, \& Kostiainen, 2016).

While many activity-based learning spaces exist in universities globally, only a few studies have reported on how these spaces are used. Baepler and Walker (2014) summarise the positive effects that active technology-enhanced learning spaces have on teaching and learning, including improvements in undergraduate student engagement, motivation, affect and learning outcomes. Such learning spaces, they observe, promote collaboration, relationship between students and educators, and shared responsibility for learning. However, there are critics of these spaces. Petersen and Gorman (2014) discuss the challenges of activity-based learning spaces. The loss of a focal point is one concern; instead of a central focus on an educator, students more actively engage with other students. Some students in their study also noted that both technology and fellow students can be distracting in an activity-based environment.

The amount of research on activity-based spaces is increasing. However, most of this literature focuses exclusively on undergraduate students (Beckers et al., 2016), often leaving research students' use of such spaces as a neglected area. In an early article on this topic, Edwards and Usher (2003) noted the scarcity of data about how research students utilise learning spaces, with research degrees often characterised as selfdefined and having little or no curriculum. It is essential, they say, to understand how research students utilise space and technology to fulfil their learning goals.

Although research student practices may appear to be less structured, the literature tends to underestimate research students' roles and their needs for learning spaces (Devos et al., 2017). Research students often come to their studies with a wide spectrum of research skills and experiences, and from various backgrounds (Hall, Quadrelli, \& Sondergeld, 2017) Research literature notes the numerous challenges that they face, including isolation (Jones, 2013); the establishment and maintenance of relationships and networks (Mantai \& Dowling, 2015); interculturality (Holliday, 2017); and supervision (Hodgson, 2017). Particular research student groups that pose additional salient challenges have been little studied, for example, mature-aged students (Fung, Southcott, \& Siu, 2017) and part-time students (Gardner \& Gopaul, 2012). One recent study (Naylor, Chakravarti, \& Baik, 2016) has observed that mature-aged research students are less likely to engage in postgraduate social activities, which can reduce their sense of belonging and thus increase attrition.

The radical transformation of knowledge and research processes is affecting how students undertake research (Hall et al., 2017). Common actions and tasks of research students increasingly include managing the vast range of digital resources, integrating formal and informal learning, and personalising and adapting learning spaces to their own needs (Keppell, 2014). While many students have a good understanding of how they learn and are able to use the available resources optimally, not all have the skills to do this effectively (Kitsantas \& Dabbagh, 2011). 
A large-scale study by Kinsley et al. (2015) on graduate students and learning spaces found:

- Graduate students value graduate-only spaces and express frustration with undergraduate-oriented spaces.

- When engaged in research or writing, graduate students are most successful when they work in a private space $(76 \%)$ or alone $(88 \%)$.

- Most graduate students (74\%) reported that they were most successful doing academic work in a quiet environment.

- Graduate students often work for long stretches of time and prefer spaces conducive to working long hours.

Kinsley et al. (2015) urge more studies of university research students, their challenges and practices, and their research degree complexities. A valuable starting point would be an appraisal of research students' needs and expectations from a learning space. This is the subject of the current study.

\section{The Space}

This study focuses on a shared activity-based workspace designed solely for research students. The Space was opened in 2016 and is unlike other research student spaces at UTS. It was built for research students within FASS and the Faculty of Health. Previously, FASS used to allocate research students to traditional workspaces comprising a fixed workstation with a table, chair and desktop computer. Availability of these spaces, however, was highly competitive and they were mostly offered to full-time and international students.

The Space is specifically designed to support and enhance research student work. It is open 24 hours a day and caters for the various needs of research students: reading and analysing, planning and writing, discussing and collaborating (UTS, 2016). It is available equally to full-time and part-time students, both international and domestic. The largest difference from the spaces used previously is that particular workstations do not belong to any one student, but are available to all as needed. According to the welcome brochure for the Space (UTS, 2016), the University has introduced these changes in order to:

- move away from a notion of one-space-suits-all

- $\quad$ increase the number of quiet and collaborative spaces

- accommodate the growing cohort of research students

- empower students to build a sense of community.

The Space provides a series of workspaces and is designed for students to move around its different zones, depending on their activities and needs. If they leave their workstation for an extended period, they are encouraged to take their belongings so that someone else can use it. Of the 151 spaces, the most common are standard workstations (82), individual pods (38) and quiet rooms (18). The rest are meeting pods (5), project spaces (2) and collaborative group spaces (6). All standard workstations feature a monitor, a quarter of them on height-adjustable desks. But there are no desktop computers; instead, FASS offers students the choice to use their own or a faculty laptop, loaned to them for their candidature. The quiet rooms are enclosed for reading, reflection and analysis but have glass walls to retain connection with the wider space. There is also a bank of more than 250 lockers and mobile drawers for secure storage. At one end of the Space is a large, modern kitchen with a glass-door fridge, microwave oven, dishwasher, chilled tap water, cutlery and crockery. Next to the kitchen is a small utility area with a multifunction printer for printing, copying and scanning.

\section{Methodology}

This leads to the main question of the paper: what are the needs and expectations of research students regarding a provided learning space? This study gathers together theoretical and methodological requirements that allow a close examination of students' insights and experiences of learning spaces. The investigative focus draws on the two methodologies: case study and hermeneutic phenomenology. A case study is bounded in some way and thus enables a close examination of the data within a specific context. Different aspects can characterise and define case studies. The most common aspect of case studies, 
including this study, involves analyses of events and experiences that are studied holistically by one or more methods and a commitment to study the complexity involved in real-life situations (Thomas, 2011).

Hermeneutic phenomenology has been selected as an overarching perspective and research method to understand the experiences of the students. It is a discipline that focuses on humans' perceptions of the world they live in and what it means to them (Langdridge, 2007); it is about lived experience, or the life world as it is lived (Van Manen, 1997). Lived experience highlights the importance of individual aspects of experience, meaning that everyone has their own unique experience (Ellis \& Flaherty, 1992).

A key principle informing the research approach in this case study is the developing of rich accounts of the lived experience of the research students. This involves recognising the dynamic, complex and situated experiences they have in the Space and examining how they make sense of these experiences. The rationale was to give voice to the research students and illuminate certain perspectives, values and sociocultural aspects (Adams, 2013).

\section{Research design}

To investigate research students' needs and expectations of the Space, the study utilised a combination of qualitative and quantitative methods. Ethics approval was obtained for the study from the university before starting the research. The research data was collected and analysed from mid-2016 until early 2017. Data used in the study consisted of three overlapping stages:

- Online survey. The survey collected data about the patterns and frequency of using the Space. It was anonymous and sent out to the students allocated to the Space. It involved multiple-choice questions (checkbox, Likert scale, multiple choice grid), and open-ended questions.

- In-depth interviews. The students utilising the Space received an email invitation to participate in a follow-up interview. The interview consisted of three parts: revisiting lived experiences; navigating the Space layout map; and reflection. First, the participants were asked to think about the Space and its usage. Second, they were invited to discuss their experiences using the layout map. Finally, the participants reflected and made sense of their expectations from the Space based on their experience in it.

- Feedback emails. The welcome brochure of the space (UTS, 2016) was distributed individually to the students who used the Space. At the back of the brochure there was an invitation to students to share feedback with the faculty through a specifically allocated email address.

Altogether, the study involved 26 data sets from FASS research students. The online survey received 15 responses. Seven students (Table 1) participated in the in-depth interviews - four were full-time students and three were part-time, while five identified as domestic and two as international students. FASS also received three emails and one oral feedback regarding the Space. The emails and feedback were shared with the authors.

Table 1

Details of interviewed research students

\begin{tabular}{lll}
\hline Student's pseudonym & Mode of study & Type of student \\
\hline Chloe & Full-time & Domestic student \\
Amelia & Part-time & Domestic student \\
Sameer & Full-time & International student \\
Gabriel & Part-time & Domestic student \\
Cooper & Part-time & Domestic student \\
Ryka & Full-time & Domestic student \\
Mira & Full-time & International student \\
\hline
\end{tabular}

\section{Data analysis}

The conceptual framework of the study consisted of case study and hermeneutic phenomenology and, therefore, required a data analysis method that would suit both. An interpretative phenomenological analysis (IPA) six-step approach (Smith, Flowers, \& Larkin, 2009) was used to analyse data from the interviews and open-ended responses to the surveys. The first analytical step is reading and rereading, 
which involves engaging with the original data. The second step includes initial noting, which resembles a free text analysis, as there are no rules or requirements, and is often the most detailed and time-consuming part. The third step deals with developing emergent themes, and step four attempts to map connections and patterns between the notes. The remaining two steps involve moving to the next case and repeating these steps and, eventually, illuminating patterns across cases. This approach provided a blueprint to highlight the voice of the participants and assisted with illuminating features that are often taken for granted.

The IPA six-step approach does not aim to gather direct, unproblematic or true facts through the surveys, interviews and texts. Rather, its focus is on understanding the students' perspectives and considering their meaningful claims and concerns.

\section{Limitations}

One of the study's limitations relates to the nature of the phenomenological process. The variety of responses indicates that some students found it rather difficult to discuss their expectations of the Space. At times they came up with one or two aspects and found it challenging to elaborate further. As well, this research occurred when the Space was relatively new. Data were collected within 6 months of using the Space. It is possible that the data may differ with subsequent years' cohorts, as some practices within the Space may change.

\section{Findings}

This section presents accounts of FASS research students and how they make sense of their needs and expectations of the Space. The accounts have been collected through interviews, survey data and feedback that FASS has received.

When students shared their lived experiences of the Space, they revealed a wide spectrum of expectations that were significant in understanding the research question. Consequently, the findings are based on data that were collected in two layers: first, survey questions and interviews about students' needs and expectations of the Space and, second, references and reflections about students' requirements based on their experiences in the Space.

The findings are summarised across three themes: physical, virtual, and hybrid space; a space free of distractions; and belonging to, and interaction with, university community. These themes emerged from the reading of the data.

\section{Physical, virtual, and hybrid space}

The first theme and a noticeable thread observed across data is that the students valued having a physical space on campus. This theme will be divided into the following four subthemes, each illustrating salient features that support student practices: physical space, hybrid workspace, virtual space and equipment, and work away from home.

Physical space

Most students referred to benefiting from having a physical office space on campus. In particular, part-time students valued the Space because previously they were unlikely to get an office space. Having a workspace on campus was presented as both a convenience and motivator to come to campus:

I wasn't really pushing my candidature ahead because I felt I am out there on my own. Once I reconnected with campus, I started coming in, became more accountable. This space gives me somewhere to go when I am here. It is that magnet ... a place where I can be. (Amelia, participant pseudonym)

In similar terms, having a physical office space motivated students to engage with life on campus. This involved not only using a desk, but also engaging with teaching, meeting supervisors, attending researchrelated events and networking. Some, in fact, pointed out that they obtained teaching or other job opportunities because they were on campus: "If there would be any real reason I ever wanted a desk, it was 
for the networking and being a part of the department. That's how I got involved with more teaching" (Amelia).

\section{Hybrid workspace}

Workspace and hybrid space were concepts commonly used to describe the environment in which the students work. For many, especially international students, the campus site was their main or only working space. For domestic and part-time students, the Space was linked with, and extended to, other workspaces, such as the university library, home, employment and other campus offices; for these students, the Space was a part of a connected and complex hybrid network.

Faculties and facilities managers often hold certain assumptions and expectations on how students should use learning spaces; for example, full-time research students should be on campus most weekdays and parttime time students less often. Data show that the real practices in the Space are far more intricate, fluid and hybrid. For instance, some part-time students interviewed used the Space several times a week, especially if they were in their final year, while some full-time students, according to the survey data, used it once a month.

Students appreciated the multipurpose nature of the Space and being able to move around its different zones according to their research activities and needs. At times a student might need a quiet area for concentrating, reading or writing, and at other times for interviewing and collaborating with others. Gabriel explained that the Space was designed for all sorts of activities. He noted that the areas for different activities were purposeful and well demarcated.

Interestingly, some students explicitly conceived of the Space as a work environment. This seems to have several benefits. For many (e.g., Amelia) the notion of being in a workspace helped to shift their mindset. Being in a work environment appeared to be conducive to doing work (Gabriel) and helped with productivity, concentration and focus (Mira). "It feels like a work environment and it gets me in the right zone", noted Gabriel. Being in a workspace also induced some behavioural norms and expectations that several students found beneficial for research work:

I almost find myself putting my phone on the silent mode when I work in here. There is something that is very rigid and disciplined about this space. Sometimes I almost feel like it makes me be that way. (Mira)

\section{Virtual space and equipment}

There was agreement among students that a physical space should work together with virtual space and equipment, including access to a stable internet connection, a printer and scanner, and both physical and electronic library services. The survey indicates that access to technology, Internet and electronic library services were rated as important for productivity by $100 \%$ of the research students.

Being able to spread out and have a place to put things comes across several narratives. For some this is related to easy and safe storage available on the premises. "No matter how paperless you are, there is stuff that you have that needs a home," reflected Amelia. Lockers, according to all interviewees, were regularly used, with the survey showing that $50 \%$ of students used lockers every time they were on campus. In the Space, students can choose either a locker from the bank of lockers or a mobile locker on wheels, depending on their work practices. This flexibility to choose was valued.

Access to a kitchen and, especially, drinkable water, tea and coffee was seen as important. Keeping the kitchen distant from workspaces, students reflected, is useful as it allows them to briefly leave the desk. Sameer recalled getting away from the desk, walking to the kitchen, drinking a glass of water and going back as moments that helped him to think outside the box. The kitchen is also used for occasional elevator conversations that appear to help students to escape their work, when needed.

\section{Work away from home}

The fourth subtheme relating to the benefits of having a workspace on campus is the opportunity to work away from home. This subtheme differs from other themes and subthemes as it is not linked to students' preferences. Instead, it illustrates an aspect that many research students attempt to avoid: working at home. 
Home was mentioned as a frequent workspace by many research students. In fact, for some it was their main workspace and was often used for last-minute writing, especially before meetings with supervisors and conferences. By working from home students also saved commuting time.

In this case study, however, six out of seven interviewed students explicitly pointed out that working from home can be challenging and at times impossible, and they preferred having a workspace away from home. Chloe chose to keep her home as a non-work and non-study space, and Gabriel indicated that there are far more distractions at home that make it difficult to focus: "I can get distracted and not achieve anything in the comfort of my own home."

Other students (Ryka, Sameer) observed that coming to campus and not working from home helped them to avoid loneliness and the feeling of being alone. Both came to campus most days because meeting with, and being surrounded by, other people encouraged and motivated them. Importantly, for many interviewees the coffee-break conversations on campus would be their only social interaction of the day. Although this was observed among most students in the study, it was particularly highlighted by international students.

The final aspect that supported research students when working away from home was having a clean and well-organised office space. According to some, maintenance of a neat home office could be challenging and at times impossible, often due to their family situation and living arrangements. Cooper explained that he shared a home office with his wife. His problem was not so much to do with the messiness, but with being “intermingled with private, business and kids' stuff". Others showcased different layers of complexity that were present when working from home. For example, working from home can take away concentration from the research project:

I prefer a tidier workspace, but that is not physically possible in my house. There is a lot of negotiating about who is working when and can I move that ... Here [at university] it is cleaner, feels more work-oriented. It's like I'm doing something with a bit more gravitas. I can leave all the piles of paper and crap at home and deal with them later. It helps de-clutter my thinking. (Amelia)

\section{A space free of distractions}

The second overall theme emerging from the data is the expectation that the learning space should be free of distractions. Quietness was the most-mentioned aspect across the surveys and interviews; each participant referred to it multiple times. No students saw it as unimportant. Of the survey participants, 93\% perceived quietness as essential to being productive, while the rest (7\%) saw it as somewhat important for this.

The way students discussed quietness, a seemingly straightforward concept, appears to be somewhat complex and fluid. A quiet space was variously referred to as the opposite of a noisy space; almost complete silence; somewhere to contemplate, concentrate and focus; and as a synonym for minimum distraction from people passing by or having background conversations. Ryka was among the few who claimed that the Space should have complete silence at all times. When asked to elaborate, she outlined certain conditions for what should and should not be allowed in the Space. These illuminate some hidden features of what she called complete silence:

There should be silence, except for occasional talking in the kitchen during the lunch hour or coffee time. That's acceptable. Phone ringing occasionally and occasional conversations in the cubicles here or there. That's just a part of a normal kind of life in an office space. (Ryka)

Similarly, Gabriel valued quietness in the Space because it helped to maintain discipline: "If there were lots of people that I knew and it was very noisy, I would probably be tempted to join in," he claimed. From that point of view, it is helpful that the Space does not get too loud, allowing students to study and focus. "It is good that there is that discipline about the space," Gabriel concluded.

Some students, by contrast, admitted that they could not work in complete silence. Amelia shared that she could not work in her previous work office - it was too quiet. When discussing the noise level in the Space, 
she said, "It is just the right amount of background hum." One of the reasons it does not get louder, she said, is that students in the space are very respectful.

In terms of specific areas in the Space, quiet rooms were among the most utilised for working. For $74 \%$ of survey participants, access to a quiet space was important for productivity, with the remaining $26 \%$ saying it was somewhat important. Approximately $35 \%$ mentioned that they used quiet rooms always or regularly when on campus. Similarly, the interviewed students referred to quiet rooms multiple times during their reflection and identified them as essential for research.

Quiet rooms are commonly utilised for quiet reading or phone calls. Once their phone calls or brief chats are over, many would leave. Students did not seem to use the room to "hang out and write in" (Amelia). Ryka and Sameer sought quiet rooms when the general noise level in the Space increased. For others, the process of shutting the door was important as it signalled wanting to be alone, leaving unwanted distractions behind the door:

Access to a really private, quiet space, being able to go and sit comfortably, and close the door in order to read and concentrate. It is really important for doing research. (Chloe)

Often implicitly, privacy came up as an essential feature in the Space. Students tended to discuss privacy in two ways. The first was in terms of having a key card-accessible working space where only research students are allowed. The survey shows that $87 \%$ perceived the locked access to premises as important for their productivity. Amelia appreciated that nobody else could access the Space.

The second way that privacy was discussed is more personal. It refers to being seen and surrounded by other people. Chloe and others agreed that being observed can be distracting. Privacy mattered significantly, especially when students were looking for a workstation to use. Some would try to go as far from others as possible, while Cooper mentioned how a wall around the pod desks helped him to hide.

Quietness and privacy come across as needs the research students required to be productive. Their responses included, but were not limited to, "silence", "quiet and friendly atmosphere", "shared work ethic", "respectful social conventions", "mindfulness of others", and "soundproof private pods". It appears that quietness and privacy should be available, yet not necessarily permanently present. The Space is designed for students to move around its different zones, depending on their needs. This zoning allows some areas to be quieter and more private than others, so that students can collaborate, when appropriate, or find a quiet space. Thus, the zoning of the Space was regarded as a supportive and purposeful.

\section{Belonging to, and interaction with, university community}

While quiet spaces with little distraction are important, so are social interactions. The third theme from the data relates to the students' expectations that they be a part of the university community. Social interactions on campus were commonly referred to as bonding with colleagues, meeting supervisors, and receiving and providing research-related feedback.

Most social interactions were not necessarily deep conversations. They were mostly labelled as "brief chats", "just a hello" or "purely professional conversations". Despite not having deep relationship with fellow researchers, most students valued any level of social connection:

I don't think they are deep relationships in the sense that you would hang out with them. We do speak and interact, but it is all about work. It is not really going beyond that, sharing personal life. They are all extremely helpful in terms of sharing information about various administrative things that need to be done or speaking about how far they have gone in their [research] project. (Mira)

Social interactions tended to be both pleasant and beneficial for work. Some of the perks of the Space, according to the students, were sharing literature and equipment, receiving general help, reflecting on individual experience or getting a different perspective: 
We don't talk as much. We talk during lunch, we walk together to the station in the evenings. If you have a confusion, you can go and ask people, especially those working in the same area. If you like to read a book and you don't have it, you can go, borrow it and talk to each other. That's very necessary to go through the $\mathrm{PhD}$ journey. (Sameer)

The social dimension appears to have motivated students to use the Space more frequently. Gabriel was a part-time student whose friend was about to start using the Space. He considered coming to the Space on the days his friend would come. "It will be a reason to go," Gabriel predicted. "I would actually know someone. We could help each other to focus and work."

Another aspect of how social interactions meet the needs of research students is through belonging and inclusion. The belonging here was experienced as being part of a community that shares similar practices, for example, the pursuit of research or academic interests. According to the survey, students in the Space were what made this community unique - they were mature and had a purpose. A series of participants indicated the benefits of being around people who understand and relate to, at least partly, what research students go through. "Sometimes it is nice to know other people who do the same thing. They kind of get it. It is like we are all in it together", concluded Amelia. Importantly, belonging to the same space and community did not have to mean being socially active. Even passive encounters were valued:

The very fact that I am going into a space where there are other students. We don't go and have a coffee, but at least we say hello. There is that contact. Before I may have seen [other research students] once a year. (Gabriel)

The way students interacted in the Space differed from person to person and from day to day. Overall, fulltime and international students were more inclined to look for socialisation opportunities. For Mira, an international student, "the most useful thing - it puts me in touch with other people who are also doing this very solitary exercise of PhD. It is nice to be among them." Part-time, domestic and final year students, although interested, were less likely to engage in long social interactions, mostly because of time pressures and other commitments. "I've got some tasks that I need to achieve. I got to tick the boxes. I'm not really here to chat. For me it's okay that I come here and not really talk to people," described Chloe.

Interactions with other students seemed to help not only with belonging to academia, but also their sanity and general well-being. Many referred to the doctoral degree being excessively individualistic and at times "very, very lonely" (Sameer). Interactions were fundamental, yet not always available. Gabriel indicated, "I am kind of used to doing [the $\mathrm{PhD}$ ] on my own, but it would be nice if I didn't have to." Sameer said, "Having that opportunity to talk to someone, who is undergoing the same journey, helps you to share and reduce your stress." It is clear that research students need a space to socialise.

Another benefit of being surrounded by research students was that it allowed them to notice the potential of how the Space was, and can be, used. Mira, for instance, revealed that she was not familiar with learning spaces like this. After using the Space for several months, it was still a new concept for her. "I am still figuring out how to best use this space," she admitted. Seeing others use the Space in their unique ways was crucial to students' considerations of its available opportunities, particularly when it was new. Several interviews illustrated the shared social practices and learning. Cooper, after using the Space for several months, reflected that he was not aware of available standing desks in the Space: "I actually just figured that out, when I saw somebody using [a standing desk] last week. I didn't know they raised up until recently."

Students observed that interactions and bonding typically happen around the kitchen area, which is at one end of the Space. While many referred to the kitchen as a synonym for meeting others, students who required quietness and focus tended to work further away from kitchen, often on the opposite side of the Space or in the quiet rooms:

If I'm in the middle of something, I would hardly want to chat. Whereas, if I've just finished something, then I would definitely want to have an in-depth chat with someone. I relax or have my coffee in the kitchen and talk to a couple of people. (Ryka) 
The kitchen was possibly the single-most used area in the Space and, interestingly, it is the area that does not have an explicit connection with research. Nearly all the survey participants (94\%) claimed they used the kitchen every time, or regularly, when on campus. As well, $80 \%$ indicated that having access to kitchen assisted them to be productive.

The kitchen provided both social and practical benefits. In a social sense, students commonly used it to connect and bond, particularly at lunchtimes. In a practical sense, it is equipped for drink and food preparation, with the toaster, sandwich maker, microwave, spacious fridge, sink, dishwasher and, most importantly, water frequently mentioned by students.

\section{Discussion}

The previous sections illustrate the experiences of research students in relation to their needs and expectations of a learning space. As a result, three themes were identified: physical, virtual, and hybrid space; a space free of distractions; and belonging to, and interaction with, university community.

The most common need regarding the learning space was a physical area where students could work. The need to work on campus came across in most of the narratives. This facilitated not only their work on the research project, but also their attendance at events and consequent networking. Most students benefited from being in an environment with several zones. The findings indicate that quiet rooms and the kitchen were among the most utilised zones in the Space, although for different purposes. Quiet rooms were for concentration and deep research, and the kitchen was for breaks and socialisation.

Participants indicated that quiet and private spaces could be as supportive to their work as social spaces. Students often require relative quietness, yet not complete and constant silence. The right amount of background hum is acceptable. Importantly, they should be able to access the quiet area at any point in time. Social interactions were equally valued, although rather difficult to achieve, mostly due to the doctoral journey generally being one of isolation and loneliness. Students claimed that having flexibility to navigate around the various zones in the Space supported their experiences and productivity.

These features come across in several studies on research students. Mantai (2017) acknowledges the need for quiet time and yet stresses that becoming a researcher usually does not happen in social isolation. Cuthbert and Spark (2008) studied isolation among research students, often referred to as a bubble, and the constant pressures caused by the mystery, secrecy and privacy of many research projects. Togetherness or social interaction, they observed, is therefore fundamental. Highlighting solidarity and the fact that many fellow students are "in the same boat" can foster confidence and collaboration.

This study shows that learning environments can change learners' practices. For many students, especially part-timers, access to the Space motivated them to come to campus more often because the new activitybased workspace assisted with their diverse needs and allowed them to be more mobile, focused and less distracted. Seeing other students using the Space also transformed some of their own practices in it. This aligns with the study by Guardino and Fullerton (2010), who noted that learners tend not only to have similar practices in the physical space, but often share meanings about their work and the way it should be organised.

It is well known that research students are vulnerable to experiencing loneliness and depression (KarpenkoSeccombe, 2016. This study shows that the Space can assist students in dealing with such challenges. Being less isolated and more socially engaged is a transformation observed across the narratives in this study. The Space was often depicted as one of just a few places where they could discuss their research. When confused or lost, they could ask other students about possible solutions.

Janta, Lugosi, and Brown's (2014) study on doctoral students coping with loneliness demonstrates correlative findings and proposes several strategies to assist with their challenges, for example, more explicit interaction with peers, and forums where doctoral students can discuss their personal journeys and professional development, including teaching, networking and attending events. While the Space at UTS provides similar opportunities, it is not yet clear how its zones are being used for social purposes; participants in this study referred to some them as being rarely used. The usage of social spaces on campus requires further research, including input from faculties and research degree program developers. 
The space encouraged students to ensure a healthy balance between work and relaxation. This finding supports Janta et al. (2014), who urge university managers to consider avenues for balancing the doctoral process and private life. Implicitly, this could include opportunities to escape the workspace and go to the kitchen for a quick break. However, more research is needed to understand how research students can better disconnect, briefly or for perhaps longer periods, from their degrees. Some scholars (e.g., Benjamin, Williams, \& Maher, 2017) warn that not being able to disconnect from the doctoral pressures can cause serious risks to a student's wellbeing. This aspect should also be considered when designing learning spaces.

\section{Conclusion}

While the amount of research on activity-based spaces is increasing, only few of such studies focus on the needs and perspectives of research students. The studies about how they utilise a learning space are scarce, and their need for a research space is frequently underestimated. This paper was concerned with examining the needs and expectations of research students regarding a learning space and urged more research in this area.

This study observed that research students are a complex group. They are not typical students in the traditional sense because research programs are less structured, individual and hybrid (Boud \& Lee, 2009), and research students tend to be more mature, independent, and rather clear on their research intentions. This can be particularly challenging for university staff when focussing on students' expectations of learning spaces. These students may need less attention in terms of teaching, yet they require more quality social and academic time with academics and fellow students.

The results of this study have shown that research students have intricate and fluid working practices, which influence their needs and expectations of a learning space. The common and often changing research practices should be feasible and reflected in the learning space design. A mix of quiet and social spaces are needed to assist students to engage with increasingly diverse research activities. A suitable learning space can positively shift student's mindset, level of motivation and sense of belonging, especially when working away from home. The results also suggest that a physical space should work together with virtual space and equipment. That includes the access not only to a stable internet connection, software, equipment and library services, but also provides access to opportunities to interact with the resources from various devices and spaces.

This study invites further investigation on how learning spaces impact on research students. It is important to not only distinguish research students' needs and expectations from those of undergraduates, but also to explore, as this study has done, how learning spaces contribute to their social, collaborative and well-being practices and allow them to move away from the often individualistic nature of research projects. It is necessary to examine how university and research degree requirements and expected outcomes encourage social practices and how learning spaces play a role in this process.

\section{Acknowledgements}

This paper is based on a research project "Students' experience of HDR learning spaces at UTS" funded by the Faculty of Arts and Social Sciences, University of Technology Sydney.

\section{References}

Adams, J. D. (2013). Theorizing a sense of place in a transnational community. Children Youth and Environments, 23(3), 43-65. https://doi.org/10.7721/chilyoutenvi.23.3.0043

Baepler, P., \& Walker, J. (2014). Active learning classrooms and educational alliances: Changing relationships to improve learning. New Directions for Teaching and Learning, 2014(137), 27-40. https://doi.org/10.1002/tl.20083

Becker, F. D. (1985). The changing paradigm for workspace. Building (unpublished data), p. 2.

Beckers, R., Van der Voordt, T., \& Dewulf, G. (2016). Learning space preferences of higher education students. Building and Environment, 104, 243-252. https://doi.org/10.1016/j.buildenv.2016.05.013 
Beichner, R. J. (2014). History and evolution of active learning spaces. New Directions for Teaching and Learning, 2014(137), 9-16. https://doi.org/10.1002/tl.20081

Benjamin, S., Williams, J., \& Maher, M. A. (2017). Focusing the lens to share the story: Using photographs and interviews to explore doctoral students' sense of well-being. International Journal of Doctoral Studies, 12, 197-217. https://doi.org/10.28945/3862

Boud, D., \& Lee, A. (2009). Changing practices of doctoral education. London: Routledge.

Boud D. (2016) Taking professional practice seriously: Implications for deliberate course design. In F. Trede \& C. McEwen (Eds.), Educating the deliberate professional: Professional and practicebased learning (pp. 157-173). Cham: Springer. https://doi.org/10.1007/978-3-319-32958-1 11

Bruno, A., \& Dell'Aversana, G. (2018). Reflective practicum in higher education: the influence of the learning environment on the quality of learning. Assessment \& Evaluation in Higher Education, 43(3), 345-358. https://doi.org/10.1080/02602938.2017.1344823

Cuthbert, D., \& Spark, C. (2008). Getting a GRiP: Examining the outcomes of a pilot program to support graduate research students in writing for publication. Studies in Higher Education, 33(1), 77-88. https://doi.org/10.1080/03075070701794841

de la Harpe, B., \& Mason, T. (2014). A new approach to professional learning for academics teaching in next generation learning spaces. In K. Fraser (Ed.), The future of learning and teaching in next generation learning spaces (pp. 219-239). Bingley: Emerald. https://dx.doi.org/10.1108/S1479$\underline{362820140000012015}$

Devos, C., Boudrenghien, G., Van der Linden, N., Azzi, A., Frenay, M., Galand, B., \& Klein, O. (2017). Doctoral students' experiences leading to completion or attrition: A matter of sense, progress and distress. European Journal of Psychology of Education, 32(1), 61-77. https://doi.org/10.1007/s10212016-0290-0

Edwards, R., \& Usher, R. (2003). Putting space back on the map of learning. In R. Edwards \& R. Usher (Eds.), Space, curriculum and learning (pp. 1-12). Greenwich, CT: Information Age.

Ellis, C., \& Flaherty, M. (1992). Investigating subjectivity: Research on lived experience. Newbury Park, CA: Sage.

Ellis, R., \& Goodyear, P. (2016). Context and implications document for: models of learning space: Integrating research on space, place and learning in higher education. Review of Education, 4(2), 192 194. https://doi.org/10.1002/rev3.3056

Fung, A. S. K., Southcott, J., \& Siu, F. L. (2017). Exploring mature-aged students' motives for doctoral study and their challenges: A cross border research collaboration. International Journal of Doctoral Studies, 12, 175-195. https://doi.org/10.28945/3790

Gardner, S. K., \& Gopaul, B. (2012). The part-time doctoral student experience. International Journal of Doctoral Studies, 7(12), 63-78. https://doi.org/10.28945/1561

Gou, Z. (2016). Workplace design revolution: The inside-out urbanism. In L. Crespi (Ed.), Design innovations for contemporary interiors and civic art (pp. 225-240). Hershey, PA: IGI Global. https://doi.org/10.4018/978-1-5225-0666-9.ch012

Guardino, C. A., \& Fullerton, E. (2010). Changing behaviors by changing the classroom environment. Teaching Exceptional Children, 42(6), 8-13. https://doi.org/10.1177/004005991004200601

Hall, J., Quadrelli, C., \& Sondergeld, A. (2017). Higher degree research students at the centre of transformational practice: An evidence based approach. In R. Walker \& S. Bedford (Eds.), Research and development in higher education: Curriculum transformation (pp. 1-12). Sydney: HERDSA. Retrieved from https://eprints.qut.edu.au/109081

Hodgson, D. (2017). Helping doctoral students understand PhD thesis examination expectations: A framework and a tool for supervision. Active Learning in Higher Education, 1-13. https://doi.org/10.1177/1469787417742020

Holliday, A. (2017). PhD students, interculturality, reflexivity, community and internationalisation. Journal of Multilingual and Multicultural Development, 38(3), 206-218. https://doi.org/10.1080/01434632.2015.1134554

Inamizu, N. (2013). Positive effect of non-territorial office on privacy. Annals of Business Administrative Science, 12(3), 111-121. https://doi.org/10.7880/abas.12.111

Janta, H., Lugosi, P., \& Brown, L. (2014). Coping with loneliness: A netnographic study of doctoral students. Journal of Further and Higher Education, 38(4), 553-571. https://doi.org/10.1080/0309877X.2012.726972

Jones, M. (2013). Issues in doctoral studies-forty years of journal discussion: where have we been and where are we going? In E. Cohen \& E. Boyd (Eds.), Proceedings of the Informing Science and 
Information Technology Education Conference (pp. 83-104). Porto: Informing Science Institute. Retrieved from https://www.learntechlib.org/p/114657

Karpenko-Seccombe, T. (2016). Supporting international PhD writers-are pastoral duties part of the package? International Student Experience Journal, 4(1), 10-16. Retrieved from http://isejournal.weebly.com/uploads/1/6/3/1/16311372/isej_manuscript tatyana_final.pdf

Keppell, M. (2014). Personalised learning strategies for higher education. In K. Fraser (Ed.), The future of learning and teaching in next generation learning spaces (pp. 3-21). Bingley: Emerald.

Kinsley, K., Besara, R., Scheel, A., Colvin, G., Brady, J. E., \& Burel, M. (2015). Graduate conversations: Assessing the space needs of graduate students. College \& Research Libraries, 76(6), 756-770. https://doi.org/10.5860/crl.76.6.756

Kitsantas, A., \& Dabbagh, N. (2011). The role of Web 2.0 technologies in self-regulated learning. New Directions for Teaching and Learning, 2011(126), 99-106. https://doi.org/10.1002/tl.448

Langdridge, D. (2007). Phenomenological psychology: Theory, research and method. Harlow: Pearson Education.

Lundström, A., Savolainen, J., \& Kostiainen, E. (2016). Case study: Developing campus spaces through co-creation. Architectural Engineering and Design Management, 12(6), 409-426. https://doi.org/10.1080/17452007.2016.1208077

Mantai, L. (2017). Feeling like a researcher: experiences of early doctoral students in Australia. Studies in Higher Education, 42(4), 636-650. https://doi.org/10.1080/03075079.2015.1067603

Mantai, L., \& Dowling, R. (2015). Supporting the PhD journey: Insights from acknowledgements. International Journal for Researcher Development, 6(2), 106-121. https://doi.org/10.1108/IJRD-032015-0007

McNeil, J., \& Borg, M. (2018). Learning spaces and pedagogy: Towards the development of a shared understanding. Innovations in Education and Teaching International, 55(2) 228-238. https://doi.org/10.1080/14703297.2017.1333917

Naylor, R., Chakravarti, S., \& Baik, C. (2016). Differing motivations and requirements in PhD student cohorts: A case study. Issues in Educational Research, 26(2), 351-367. Retrieved from http://www.iier.org.au/iier26/naylor.pdf

Pegrum, M. (2016). Future directions in mobile learning. In D. Churchill, J. Lu, T. K. F. Chiu, \& B. Fox (Eds.), Mobile learning design: Theories and application (pp. 413-431). Singapore: Springer. https://doi.org/10.1007/978-981-10-0027-0_24

Petersen, C. I., \& Gorman, K. S. (2014). Strategies to address common challenges when teaching in an active learning classroom. New Directions for Teaching and Learning, 2014(137), 63-70. https://doi.org/10.1002/t1.20086

Sawers, K. M., Wicks, D., Mvududu, N., Seeley, L., \& Copeland, R. (2016). What drives student engagement: is it learning space, instructor behavior or teaching philosophy? Journal of Learning Spaces, 5(2), 26-38. Retrieved from http://libjournal.uncg.edu/jls/article/view/1247

Skogland, M. (2017). The mindset of activity-based working. Journal of Facilities Management, 15(1), 62-75. https://doi.org/10.1108/JFM-05-2016-0016

Smith, J., Larkin, M., \& Flowers, P. (2009). Interpretative phenomenological analysis: Theory, method and research. London: Sage.

Strayer, J. F. (2012). How learning in an inverted classroom influences cooperation, innovation and task orientation. Learning Environments Research, 15(2), 171-193. https://doi.org/10.1007/s10984-0129108-4

Thomas, G. (2011). A typology for the case study in social science following a review of definition, discourse, and structure. Qualitative Inquiry, 17(6), 511-521. https://doi.org/10.1177/1077800411409884

University of Technology Sydney. (2016). Shared HDR activity-based workspace. Sydney: University of Technology Sydney.

Van der Voordt, T. J. (2004). Productivity and employee satisfaction in flexible workplaces. Journal of Corporate Real Estate, 6(2), 133-148. https://doi.org/10.1108/14630010410812306

Van Manen, M. (1997). Researching lived experience: Human science for an action sensitive pedagogy. London, ON: The Althouse Press.

Vercellotti, M. L. (2017). Do interactive learning spaces increase student achievement? A comparison of classroom context. Active Learning in Higher Education, 19(3), 1-14. https://doi.org/10.1177/1469787417735606

Wilson, G., \& Randall, M. (2012). The implementation and evaluation of a new learning space: A pilot study. Research in Learning Technology, 20(2), 1-17. https://doi.org/10.3402/rlt.v20i0.14431 
Corresponding author: Sandris Zeivots, $\underline{\text { Sandris.Zeivots@uts.edu.au }}$

Australasian Journal of Educational Technology (C) 2018.

Please cite as: Zeivots, S., \& Schuck, S. (2018). Needs and expectations of a new learning space: Research students' perspectives. Australasian Journal of Educational Technology, 34(6), 27-40. https://doi.org/10.14742/ajet.4516 